\title{
Repetência e abandono no ensino público regular: representações sociais da produção do "fracasso escolar"
}

\section{Grade repetition and dropout in regular public education: social representations of the production of "school failure"}

\author{
Luciene Alves Miguez Naiff (orcid.org/0000-0002-7075-9579)' \\ Denis Monteiro Naiff (orcid.org/0000-0002-1031-0980)2
}

\begin{abstract}
Resumo
O principal objetivo do presente artigo foi identificar representações sociais de alunos de escolas públicas da Região Metropolitana do Estado do Rio de Janeiro em relação à evasão escolar e à repetência, além de mapear os fatores propulsores e inibidores da construção da identidade de "estudante" na vida dos alunos. As etapas escolares interrompidas na Educação Básica em regime regular afetam a dinâmica psicossocial envolvida nas decisões dos alunos na sua vida profissional e na perspectiva de futuro. A partir do referencial teórico da Teoria das Representações Sociais e, de forma complementar, pela Teoria da Identidade Social, procurou-se compreender os fenômenos relacionados ao "fracasso escolar". Foram entrevistados 430 estudantes do ensino fundamental. Os dados foram analisados com o auxílio do software EVOC 2003 para levantamento do possível núcleo central das representações, e o software SPHINX foi utilizado no auxílio da tabulação dos dados e construção dos instrumentos.
\end{abstract}

Palavras-chave: Representações sociais. Evasão escolar. Repetência. Educação Básica. Identidade social.

\begin{abstract}
The main objective of this article was to identify social representations of students from public schools in the Metropolitan Region of the State of Rio de Janeiro in relation to school dropout and grade repetition, as well as to map the driving and inhibiting factors of the construction of the "student" identity in the students' lives. The school stages interrupted in regular Basic Education on a regular basis affects the psychosocial dynamics involved in students' decisions in their professional life and in their perspective of the future. Based on the theoretical framework of the Social Representations Theory and, in a complementary way, on the Social Identity Theory, we sought to understand the phenomena related to "school failure". A total of 430 elementary school students were

\footnotetext{
1 Universidade Federal Rural do Rio de Janeiro, Seropédica, Brasil. E-mail: lunaiff@hotmail.com.

2 Universidade Federal Rural do Rio de Janeiro, Seropédica, Brasil. E-mail: dnaiff@ufrrj.br.
} 
interviewed. The data were analyzed with the help of EVOC 2003 software to survey the possible central core of the representations and the SPHINX software was used to assist in the tabulation of the data and the construction of the instruments.

Keywords: Social representations. School dropout. Grade repetition. Basic Education. Social identity.

A escola e o processo educacional brasileiro, principalmente em seu segmento fundamental, têm sofrido inegáveis avanços nas últimas décadas do século XX e nas primeiras do século XXI. Atualmente, mais de $97 \%$ das crianças com idade escolar são absorvidas nas vagas oferecidas ao $1^{\circ}$ ano do ensino fundamental, com aproximadamente $2 / 3$ alocadas na rede pública de ensino e apenas $18 \%$ presentes em rede privada; mantendo, dessa forma, um preceito constitucional do Estado como garantidor de educação básica gratuita à população e apontando para uma universalização do acesso à educação formal (Inep, 2016; Oliveira, Borgui \& Miranda, 2018).

No entanto, em 2005, de cada 5,57 milhões de crianças que entravam no ensino fundamental (antiga $1^{\text {a }}$ série), apenas 4,19 milhões chegavam ao $6^{\circ}$ ano (antiga $5^{\text {a }}$ série) e 3,27 milhões ao $9^{\circ}$ ano (antiga $8^{a}$ série), o que significava aproximadamente 2,3 milhões de crianças que não conseguiam acompanhar a relação idade/série esperada. Os censos recentes ainda mostram uma escala progressiva de fracasso que aumenta consideravelmente dos anos iniciais até o ensino médio, sendo essa etapa a de maior evasão em todo o território nacional (Inep, 2016). Esse é um fator importante a ser investigado, pois os números mostram que, devido aos índices de reprovação e evasão considerados altos, a escola brasileira apresenta dificuldade em garantir, nos nove anos do ensino fundamental, o aproveitamento necessário, principalmente das classes menos favorecidas, o que leva, consequentemente, a um aproveitamento ainda pior no ensino médio (Arevalo, 2005). Dados de 2011 mostram que as escolas públicas brasileiras apresentam no Índice de Desenvolvimento da Educação Básica ${ }^{3}$ (Ideb) média de 3,9,

3 O Ideb foi criado pelo Instituto Nacional de Estudos e Pesquisas Educacionais Anísio Teixeira (Inep), do Ministério da Educação, sendo hoje o principal indicador da educação brasileira. Ele mede o desempenho do sistema educacional pela combinação de dois fatores: o resultado dos estudantes na prova Brasil (Português e Matemática) e a taxa de aprovação. 
enquanto nas escolas particulares essa média é de 6,2 no $9^{\circ}$ ano do ensino fundamental. Nos anos iniciais ( $5^{\circ}$ ano), houve aumento considerável da média, que em 2005 era de 3,6 nas escolas públicas e passou para 4,7 em 2011, enquanto nas escolas particulares a média é de 6,6 em 2011 . Ainda que se comemore o aumento das médias (principalmente nos anos iniciais), o disparate entre as redes privada e pública reflete o tipo de educação que está sendo oferecida e aproveitada pela população menos favorecida economicamente, tornando o risco de insucesso na rede pública alarmante em se comparada à rede privada (Inep, 2011 , 2016).

Temos no Brasil um grande número de jovens entre 18 e 24 anos que só trabalham $(46,7 \%)$, e $27,4 \%$ que nem trabalham nem estudam, a chamada geração "nem nem". Ou seja, toda uma geração que não continuará seus estudos até o nível superior, e muitos desses nem mesmo concluirão o ensino médio (IBGE, 2010), reflexo de uma realidade que começa bem antes, ainda na infância e na adolescência. Entre 4 e 17 anos, existem 3,8 milhões fora da escola, isso equivale a $8 \%$ de indivíduos nessa faixa etária em todo o Brasil. A maioria das crianças que não estudam, entre 6 e 14 anos (62\%), chegou um dia a frequentar a escola, mas a abandonou. Temos 1 milhão de crianças nessa faixa etária fora da escola (Gois \& Rocha, 2012).

Mesmo sendo a educação um direito garantido em várias legislações brasileiras, e, em se tratando de crianças e adolescentes, um direito básico, os exemplos de crianças em idade escolar sem estudar não estão restritos às cidades mais pobres. Também nos grandes centros urbanos, onde a desigualdade social é um grave problema, encontramos crianças e adolescentes em situação de risco social com dificuldade de se manterem nos bancos escolares de forma contínua (Gois \& Rocha, 2012). As políticas públicas de transferência de renda, em que a matrícula e a frequência escolar são uma obrigatoriedade, tentam minimizar essa circulação das crianças dentro e fora das escolas, mas ainda apresentam uma repercussão negativa no que tange à permanência sem interrupção e ao aproveitamento.

O presente estudo pretende explorar o fenômeno chamado "fracasso escolar" por meio do arcabouço teórico e metodológico oferecido pela Psicologia Social. Para tanto, 
iremos investigar a formação da identidade social de estudante na vida de alunos do ensino fundamental e identificar suas representações sociais em relação aos fatores envolvidos nos casos de repetência escolar e abandono nas escolas públicas da Região Metropolitana do Rio de Janeiro localizadas em quatro municípios alvos da pesquisa, que são: Seropédica, Nova Iguaçu, Niterói e Rio de Janeiro.

\section{A escola como espaço de inclusão social}

A discussão sobre a escola como agente de inclusão ou exclusão social pode ser exemplificada quando nos deparamos com as implicações sociais de dados que mostram que o sistema educacional brasileiro ainda apresenta índices de evasão escolar e defasagem idade/série incompatíveis com os projetos de desenvolvimento da sociedade associados à educação formal. Segundo a Sinopse Estatística da Educação Básica de 2009 (Inep, 2009), o estado do Rio de Janeiro apresentava em 2008 16\% de taxa de reprovação dos alunos no ensino básico, com $24,4 \%$ no $6^{\circ}$ ano, ou seja, praticamente um aluno em cada quatro matriculados no $6^{\circ}$ ano do ensino fundamental era reprovado ao final do ano letivo. Como uma das prováveis consequências da reprovação, encontramos no estado 3,1\% de taxa de evasão, com $4,7 \%$ no $6^{\circ}$ ano e $5,1 \%$ no $9^{\circ}$ ano. No ensino médio as taxas aumentavam, em média, para 19,6\% de reprovação e 13,8\% de evasão dos alunos.

No Brasil como um todo, a defasagem idade/série atinge $23,3 \%$ de todas as crianças e adolescentes do ensino fundamental e $34,5 \%$ no ensino médio, dados ainda presentes nos censos mais recentes (Inep, 2010, 2016)

Muitos estudos investigam as causas da existência em nosso sistema educacional tanto de excluídos da escola, indivíduos em idade escolar que deveriam estar frequentando a escola, mas que por diversos motivos constavam como evadidos; quanto os excluídos na escola, estudantes que mesmo estando matriculados e cursando a escola, por força de sucessivas reprovações, acusavam forte defasagem idade/série em seus estudos (Patto, 1988, 2010; Ferraro \& Machado, 2002). 
Dados da literatura também apontam para a correlação direta entre indicadores de reprovação, defasagem série/idade e consequente evasão escolar de um contingente significativo das crianças brasileiras, condenadas precocemente a uma provável exclusão social ocasionada pela baixa escolaridade formal acumulada, que, em última análise, dificultará a inserção no mercado de trabalho (Leon \& Menezes-Filho, 2002). As tentativas de mudanças na pedagogia da repetência no sistema educacional público brasileiro, historicamente, tem encontrado resistências na classe docente, atores sociais fundamentais no processo educativo (Neves \& Almeida, 1996; Mattos, 2005; Souza, 2006; Naiff \& Naiff, 2011 ). Essas são questões cruciais no campo da Educação e um importante fenômeno para a Psicologia Social voltada ao estudo dos fenômenos escolares. A Educação é uma das principais preocupações da agenda social brasileira, mas como política pública acaba sofrendo descontinuidades resultantes das mudanças governamentais (Fernandes \& Franco, 2001 ; Parente, 2018).

O "fracasso escolar", portanto, é um problema multifacetado que desafia as áreas de saber que pretendem encontrar formas de entendê-lo e sobre ele intervir. Silva (2018) argumenta, inclusive, que ao lidarmos com a Educação pensando somente em resultados, perdemos um de seus principais aspectos, que é a vivência social e política, em síntese: o ato em si de estudar e a identidade de ser um estudante. É nesse sentido que a Psicologia Social vem se debruçando sobre esse fenômeno, propondo um olhar que incide sobre as percepções, atitudes, representações sociais, relações interpessoais e identidade.

\section{Representações sociais e identidade social: aportes teóricos}

É no universo sociocultural que estão e são continuamente produzidas as representações sociais. Se quisermos compreender por que uma pessoa se comporta de um jeito e não de outro, devemos ver as relações sociais embutidas em seu cotidiano. Nossas reações frente a outras pessoas estão em grande parte mediadas pelas percepções e representações sociais que fazemos delas (Moscovici, 2003). 
Quando falamos de crianças e adolescentes, o contexto em que estão inseridas é ao mesmo tempo espaço de expressão de sua subjetividade e também de aprendizagem e aquisição de valores e crenças; portanto, enquanto indivíduos em formação, as crianças adquirem sua compreensão sobre o mundo e sobre si mesmas em seus grupos de pertença, desde os mais básicos e primários, como a família, até os grupos sociais variados nos quais tenham diferentes graus de inserção, seja por afinidade, parentesco, tarefa, seja por lazer, etc.

A escola é, nesse sentido, um espaço de interação social marcado tanto pela aquisição de novos conhecimentos quanto pela socialização com os pares. Segundo Gilly (2001, p. 322), o crescente interesse do estudo das representações sociais na área da Educação se deve exatamente por sua relevância social e potencial de mobilização dos atores envolvidos.

Dada a importância crucial que lhe atribuem as diferentes partes envolvidas (administradores, dirigentes centrais, agentes do sistema e usuários) o "fracasso escolar" e as desigualdades sociais face à escola estão entre os temas que melhor revelam os aspectos centrais das representações que sustentam os diferentes discursos a esse respeito.

Essas considerações servem para ilustrar como professores e alunos organizam, interpretam, e constroem algumas representações mútuas que irão mediar suas relações.

O conceito de representação social diz respeito ao conhecimento do senso comum, que é gerado no ambiente social em que os sujeitos estão inseridos e tem funcionalidade na vida prática - pode-se dizer que corresponde ao pensamento social existente em um grupo. Uma definição muito bem aceita no campo de estudos das representações sociais e que resume suas principais características é dada por Jodelet (1984, pp. 361-362), ao afirmar que "As representações sociais são modalidades de pensamento prático orientadas para a comunicação, a compreensão e o domínio do ambiente social, material e ideal. Enquanto 
tais, elas apresentam características específicas no plano da organização dos conteúdos, das operações mentais e da lógica”.

As representações sociais têm, segundo Abric (1994, 2003), uma organização significante, isto é, não são apenas reproduções da realidade, estão imersas em um contexto mais imediato e outro mais global. Respondem a quatro perguntas em sua composição: quem representa? (o sujeito); quando representa? (o momento histórico); a partir de onde representa? (contexto social); e por que representa? (o objetivo) (Jovchelovitch, 1996).

Este artigo teve como objetivo geral levantar fatores responsáveis pelo chamado "fracasso escolar", definido como repetência e abandono na Educação Básica, ${ }^{4}$ por meio da identificação das representações sociais de alunos de escolas públicas da Região Metropolitana do Estado do Rio de Janeiro em relação à evasão escolar e à repetência. Como objetivo secundário, tencionou mapear os fatores propulsores e inibidores da construção da identidade de "estudante" na vida dos alunos. A pesquisa foi realizada na região Metropolitana do Rio de Janeiro em quatro cidades, a saber: Rio de Janeiro, Niterói, Nova Iguaçu e Seropédica, escolhidas pelas diferenças geográficas e sociais que apresentam.

\section{Método}

\section{Procedimentos de coleta de dados e aspectos éticos}

O presente artigo é um dos desdobramentos de uma pesquisa de larga escala acerca da Educação no Brasil, com enfoque em diversas temáticas relevantes à interface entre Educação e Psicologia Social. A temática aqui representada trata do chamado "fracasso escolar". A pesquisa conta com uma coordenação docente e discentes de todos os níveis de formação.

\footnotetext{
4 A Educação Básica é composta pela Educação Infantil, ensino fundamental e ensino médio. A presente pesquisa se deterá nos segmentos fundamental e médio, que apresentam os índices mais preocupantes de repetência e evasão.
} 
Os participantes responderam ao instrumento de pesquisa mediante seu assentimento expresso e autorização dos responsáveis (assinatura do Termo de Consentimento Livre e Esclarecido - TCLE), no caso dos menores de 18 anos. Após a autorização dos responsáveis, a coleta de dados dos questionários foi feita de forma grupal.

A partir do estudo empírico, identificamos as representações sociais de 430 alunos sobre fenômenos relacionados à escola, ao estudar, e a relação do estudo com o futuro e elementos propulsores e inibidores da identidade de estudante. Esses alunos foram selecionados aleatoriamente, após prévia consulta e consentimento dos responsáveis em escolas localizadas nos municípios mencionados. O ponto de corte da amostra era a necessidade de o aluno estar na Educação Básica e cursando do $5^{\circ}$ ano do ensino fundamental ao ensino médio.

Foram utilizados questionários com os alunos com questões fechadas e abertas, e tarefa de evocação livre utilizando termos indutores adequados aos objetivos do estudo.

Os dados qualitativos obtidos com as entrevistas foram analisados por intermédio de análise de conteúdo (Bardin, 1977; Bunomo, Trindade, Souza \& Coutinho, 2008, p. 161).

\section{Caracterização da amostra}

Responderam aos instrumentos 430 alunos de escolas públicas. Destes, 429 estudavam no momento da pesquisa e um relatou não estar estudando. Duzentos e nove estudantes estavam no primeiro ano do ensino médio; quatro estavam no $8^{\circ}$ ano do ensino fundamental; 92 , no $7^{\circ}$ ano do ensino fundamental; 122 , no $6^{\circ}$ ano do ensino fundamental; e três no $5^{\circ}$ ano do ensino fundamental.

As idades variam de 10 a maiores de 18 anos. No intervalo entre 10 e 13 anos, 162 alunos responderam; entre 14 e 18, foram 263 alunos respondentes, com mais de 18 anos, sete alunos. Em relação ao gênero, 197 eram do sexo masculino e 229 do sexo feminino quatro não responderam.

Quanto à retenção e reprovação, 248 estudantes nunca ficaram retidos, enquanto 182 já repetiram a série estudada; 386 nunca chegaram a parar os estudos, enquanto 44 
pararam; 309 alunos relatam nunca ter pensando em parar, contra 121 que já pensaram em desistir.

$\mathrm{Na}$ comparação feita entre os alunos do ensino fundamental e médio, não foram apresentadas diferenças que pudessem ser consideradas importantes para tratá-los como grupos diferentes em relação às questões levantadas, Por esse motivo, optamos por trabalhar com um corpus geral de 430 sujeitos.

\section{Resultados}

Foi apresentado um termo indutor aos alunos para que dissessem o que the viesse à mente diante da palavra ESTUDAR. A seguir temos a representação do quadro de quatro casas com a possível estrutura das representações sociais dos alunos de escolas públicas da amostra pesquisada.

Figura 1. Quadro de quatro casas com o termo indutor: Estudar

$$
<2,5 \text { ordem média de evocação } \geq 2,5
$$

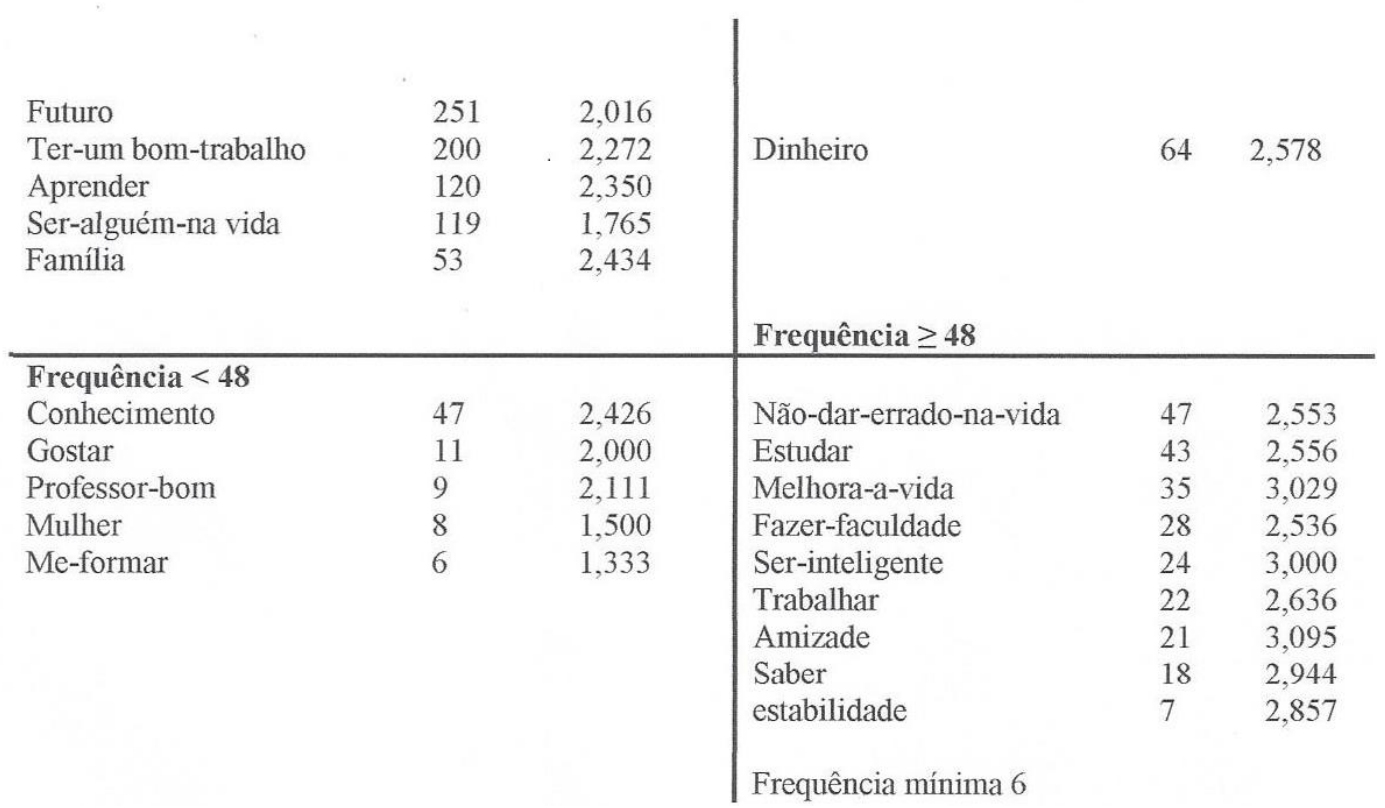

Fonte: Elaborada pelos autores. 
No provável núcleo central, estudar está relacionado a futuro, ter um bom trabalho, aprender, ser alguém na vida e família. Os termos relacionados à visão da escola como uma oportunidade são preponderantes, portanto, existe uma atitude positiva em relação a esse espaço. No entanto, essa é uma representação social hegemônica da escola. Ou seja, propagada em larga escala na sociedade, de forma que aparece em representações sociais de grupos sociais diversos (Silva, 2018). Família é um cognema mais particular, pois se refere a ajudar a família, a mudar a vida da família ou a dar orgulho à família. Esse componente das representações sociais aparecendo no núcleo central nos mostra que a Educação é um fator diferencial na intergeracionalidade em relação à escolarização das famílias mais empobrecidas.

O dinheiro aparece no segundo quadrante, mostrando a relação direta entre escolarização e melhores oportunidades. A zona de contraste mostra uma diferença em relação aos outros quadrantes, podendo representar um subgrupo que percebe o estudar como algo que tem suas vantagens, mas que é apreciado na vivência diária. Ou seja, estar na escola tem significados importantes e não apenas para projetar a escola para um possível futuro melhor (Naiff \& Naiff, 2014).

O quadrante mais distante do núcleo central mescla a visão mais difundida da escola com as impressões reais e cotidianas de estudar. Não dar errado na vida é bem significativo e ficou próximo de compor o segundo quadrante, significando uma outra oportunidade àquelas que são oferecidas aos jovens empobrecidos brasileiros e que os levam a vulnerabilidades diversas. Essa realidade, em especial no Estado do Rio de janeiro, não pode ser negligenciada. A escola disputa, e não raro, perde os jovens para o crime organizado, que os arregimenta, ainda bem novos, e fazem qualquer outra opção ficar em segundo plano; além do subemprego e da formação de uma família para uma entrada na vida adulta precocemente (Leon \& Menezes-Filho, 2002; Naiff \& Naiff, 2011; Ruiz, Silva \& Batista, 2017).

A seguir apresentamos os dados da análise de conteúdo das perguntas abertas, a partir da técnica de categorização proposta por Bardin (1997), em que levamos em conta a frequência de aparição das categorias, assim como o conteúdo que elas apresentam. 
Os alunos foram indagados sobre gostar da escola, dos motivos que levam à retenção de ano, os motivos que facilitam e prejudicam os estudos, os motivos que levam à não aprendizagem e os motivos para ir ou não à escola. Em relação aos dados mais específicos da condição escolar, 329 relataram gostar de estudar e 97 não gostam, quatro não responderam.

Quadro 1. Motivos para repetir o ano

\begin{tabular}{lcl}
\hline \multicolumn{1}{c}{ Categorias } & Frequência & \multicolumn{1}{c}{ Unidades de registro } \\
\hline Falta de motivação & 230 & "São desinteressados ou não se esforçam o \\
& & $\begin{array}{l}\text { suficiente" } \\
\text { "Não se interessam no estudo" }\end{array}$ \\
& & "Porque não estudam e faltam muito" \\
& & "Não estuda, fica só de brincadeira na aula" \\
Faltas escolares & & "Vive na internet" \\
& & "As drogas" \\
Fatores & 35 & "Más influências" \\
extraescolares & &
\end{tabular}

Fonte: Elaborado pelos autores.

Em relação à retenção de ano (Quadro 1), os alunos apontam motivos pessoais de uma maneira geral, sendo a falta de interesse, de dedicação e de atenção os principais. Há um relato relacionado à própria vivência de cada um, mas também reproduzido pelos professores, como vimos nos quadros referentes a esses atores. Ou seja, o aluno vê a si próprio e a seus pares como culpados pelo insucesso escolar. Esse dado nos indica que o processo, chamado por Patto (2010) de fracassalização do aluno pobre, ainda se mantém. Percebemos um processo de profecia autorrealizadora (Rodriguez, Assmar \& Jablonski, 2006) que categoriza os indivíduos em padrões dos quais eles não conseguem avançar e com isso reproduzem esse discurso, agindo de forma a dar coerência a ele.

O que prejudica os estudos segue a mesma lógica do que leva à retenção, a culpa no aluno. Já os motivos que levam à facilitação da Educação mesclam motivos diretamente 
relacionados com a escola com motivos pessoais e sociais. Percebemos aqui uma visão generalista do que pode apoiar o estudo, mas ainda sem uma visão mais crítica. No entanto, todos os elementos essenciais aparecem, quais sejam, motivos ligados à escola em si, motivos pessoais e familiares. Portanto, não há uma falta de entendimento do que pode facilitar ou prejudicar os estudos, mas há um cotidiano que os impele ou os leva a outras escolhas.

Quadro 2. Motivos para não aprender

\begin{tabular}{lcl}
\hline \multicolumn{1}{c}{ Categorias } & Frequênci & \multicolumn{1}{c}{ Unidades de registro } \\
\hline Motivos relacionados & 423 & "Por que elas não interessam em aprender" \\
aos alunos & & "Porque brincam quando os professores \\
& explicam" \\
& "Não prestam atenção" \\
& & "Têm dificuldade em aprender ou não \\
& & querem" \\
\hline Motivos relacionados à & 22 & "Talvez os professores não saibam explicar \\
escola & de um jeito melhor para entenderem" \\
& "Os professores saírem dando a matéria no \\
& quadro e não explicam \\
& "O professor não sabe ensinar"
\end{tabular}

Fonte: Elaborado pelos autores.

No Quadro 2, vemos que os motivos que preponderam são pessoais. A aprendizagem durante muito tempo foi atribuída apenas ao aluno. O uso da expressão ensino-aprendizagem muda essa configuração para uma relação díade. Entretanto, ainda que os alunos percebam que existe uma parcela de responsabilidade no ensino, eles atribuem a si mesmos os principais motivos de não aprenderem, corroborando os dados relativos à retenção e ao que prejudica os estudos (Inep, 2016; Naiff \& Naiff, 2014). 
Importante salientar que os alunos não responderam de si mesmos, mas foram levados a falar de seu grupo social, ou seja, o que faz os alunos de escolas públicas não conseguirem aprender? As respostas mostram os fatores atribuídos por eles aos seus grupos de pertença, retirando o peso da tendenciosidade atribucional que poderia fazê-los querer proteger suas próprias histórias e escolhas.

Quadro 3. Motivos para não ir à escola

\begin{tabular}{|c|c|c|}
\hline Categorias & $\begin{array}{c}\text { Frequênci } \\
\text { a }\end{array}$ & Unidades de registro \\
\hline $\begin{array}{l}\text { Fatores relacionados } \\
\text { aos alunos }\end{array}$ & 339 & $\begin{array}{l}\text { "São muito preguiçosos e não querem estudar" } \\
\text { "Falta de vontade e desânimo" } \\
\text { "A escola não seduz os alunos e, às vezes, é, até } \\
\text { mesmo, chata. } \\
\text { "Estão desestimulados" ou "Não têm incentivo" } \\
\text { "Acham uma perda de tempo" }\end{array}$ \\
\hline $\begin{array}{l}\text { Fatores relacionados à } \\
\text { escola }\end{array}$ & 25 & $\begin{array}{l}\text { "Não querem estudar ou as escolas não oferecem } \\
\text { bom ensinamento" } \\
\text { "Porque eles não gostam de ir, porque os } \\
\text { professores são ignorantes" } \\
\text { "Sofrem bullying" }\end{array}$ \\
\hline $\begin{array}{l}\text { Fatores externos à } \\
\text { escola }\end{array}$ & 37 & $\begin{array}{l}\text { "Muitas pessoas não estudam porque ficam } \\
\text { trabalhando para colocar dinheiro" ou "Ficam em } \\
\text { casa mexendo no telefone, computador, etc." } \\
\text { "Às vezes engravida" } \\
\text { "Por causa do mundo do crime" }\end{array}$ \\
\hline
\end{tabular}

Fonte: Elaborado pelos autores.

Os motivos para não querer ir à escola, observados no Quadro 3, também são majoritariamente pessoais, culpabilizando o aluno quase que integralmente. Apesar de 
aparecer novamente a escola e fatores externos, esses não são tão marcantes e definidores dos motivos de absenteísmo na escola pública.

O aluno, apesar de positivar estudar e aprender, se vê em todas as perguntas feitas como o principal culpado por isso não acontecer. Não percebem de forma marcante o contexto escolar, o contexto social, suas necessidades e desejos e o laço que a escola deveria formar com eles. Isso fragiliza sobremaneira sua identidade de estudante, pois entra em conflito com o que acredita ser a melhor forma de aproveitar a escola. Se ser interessado, estudioso e ter atenção são sinônimos de bom desempenho, não ter isso é sinônimo do fracasso. Ou seja, nesse sentido, são eles os únicos culpados pelo insucesso escolar, então, desistir se torna uma saída diante do cenário apresentado, já que essa é uma atribuição de causa que provoca desânimo e desistência, pois carrega culpa e frustração de não poder ou conseguir ser diferente ou ser visto de forma diferente (Ferreira et al., 2002; Naiff, Sá \&Naiff, 2008).

\section{Discussão dos resultados}

Os resultados apontam sempre para uma individualização do fenômeno, tendo como causa principal características pessoais e sociais do aluno e em segundo lugar de sua família (Wilson, 2003; Alves-Mazzotti, 2010; Naiff, Benevides, Naiff \& Souto, 2010; Zonta \& Meira, 2007; Abranches, 2000; Castorina \& Kaplan, 1997; Franco, 2002; Hollanda, 2001; Maluf \& Bardelli, 1991; Neves \& Almeida, 1996; Rangel, 1997).

Deschamps e Moliner (2009) consideram que os interesses grupais e as dinâmicas intra e intergrupais direcionam a construção das representações sociais. Conforme salientam Pereira, Amaral e Soares (1997), existiriam três modos como as identidades sociais podem condicionar a produção de representações sociais. Em primeiro lugar, a informação disponível sobre o objeto, isto é, se os membros do grupo estão informados sobre aspectos do objeto de tal modo que a respectiva representação sirva os interesses do grupo; em segundo lugar, as comunicações explícitas dos membros do grupo influenciam a aceitação ou rejeição de uma determinada representação do objeto; em terceiro lugar, essas 
comunicações determinam também a frequência de uso de representações sociais sobre os objetos em questão. Nos dados apresentados, percebemos os alunos falando de seus pares de acordo com suas vivências cotidianas. Ou seja, a escola, apesar de positivada, não exerce atratividade suficiente para que a identidade de estudante se imprima de forma marcante nesse grupo.

De acordo com Tajfel (1982), precisamos de uma identidade social para nos posicionar na sociedade, pois é a partir dessa identidade que iremos direcionar nossos afetos, nossas ações e nossas escolhas. Incluímo-nos em um grupo social e a partir dessa inclusão sabemos quem somos e quem não somos, ou seja, definimo-nos por afinidades ao nosso grupo e rejeição aos valores e ideias do outro grupo ou exogrupo. É comum entre os jovens mais empobrecidos perceberem o tempo gasto na escola como perda de tempo diante de outras vontades e necessidades (Gois \& Rocha, 2012; Silva, 2018). Ser um estudante e fracassar se torna mais desestimulante do que simplesmente não frequentar a escola, e, com isso, não se deparar com fragilidades que, em última análise, eles atribuem a si mesmos (Naiff et al., 2012).

Em uma sociedade que valoriza tanto a Educação, que deu margem à disseminação de representações sociais sólidas na cultura brasileira, como o "lugar de criança é na escola" e "se não estudar não será ninguém na vida", a identidade de "estudante" é automaticamente relacionada às crianças, adolescentes e jovens. Isso quer dizer que incutimos desde cedo nas crianças a ideia de que precisam estudar e que a Educação é importante para a ascensão social. No entanto, ainda que essa seja uma questão normativa no Brasil, percebemos que os alunos das escolas públicas oriundos de camadas muito empobrecidas têm vínculos fragilizados com a escola, gerando uma grande circulação entre a Educação formal e a necessidade de geração de renda. Associado a esse fenômeno, os dados da pesquisa com os alunos do EJA (Naiff et al., 2012) mostraram mecanismos atribucionais de ordem interna, em relação ao desempenho escolar, traduzidos em dificuldade de aprender e desinteresse, fator corroborado em outras pesquisas com estudantes de escolas públicas brasileiras (Ferreira et al., 2002). Ou seja, os alunos param de estudar para trabalhar e, além disso, atribuem suas dificuldades na escola a aspectos 
internos, o que pode servir de empecilho para a volta ou a continuidade da Educação formal, já que, segundo pesquisas dessa área da Psicologia Social, provocam baixa autoestima e sentimentos de vergonha e impotência (Naiff, Sá \& Naiff, 2008; Rodrigues, Assmar \& Jablonski, 2007).

É relevante pensar que a formação das identidades sociais é marcada culturalmente e socialmente, de tal forma que grupos sociais pertencentes a uma mesma sociedade podem vivenciar essas relações diferentemente, de acordo, por exemplo, com sua classe social ou gênero. A importância que se dá à escola, portanto, é gerada em um discurso socialmente compartilhado por grupos com os quais os indivíduos se identificam, mas para que esse discurso gere práticas sociais correspondentes, o cotidiano desses indivíduos deve estar a serviço da manutenção dessa proposta. Como consequência, a importância que se dá à escola passaria de um discurso esvaziado de sentido para representações sociais que guiem de fato comportamentos de manutenção e motivação com o ciclo escolar, E isso só pode acontecer no interior dos grupos sociais. Se a criança aprende que deve estudar, mas percebe que sua condição social cria demandas que vão para além dos muros escolares e a escola, em vez de absorvê-la com suas demandas, aponta sua diferença como uma inadaptação, essa escola irá gradativamente deixando de ser uma possibilidade em prol de um futuro melhor para que o trabalho e outras formas de afirmação social thes deem um melhor posicionamento no presente. Segundo Bunomo, Trindade, Souza e Coutinho (2008, p. 57), as imbricações entre as identificações e as diferenciações sociais que produzimos são "mediadas por mediadoras das representações que se tem de determinado grupo social".

Deschamps e Moliner (2009) nos orientam para a necessidade de levar em conta na formação da identidade social a avaliação que o indivíduo tem de si mesmo, do seu grupo de pertença, do que pensa que os outros pensam dele, de suas explicações para seu sucesso e seu fracasso e pela forma como encaram o futuro. Esse pode ser um dos motivos para que os índices das escolas privadas acabem sendo bem mais positivos em relação à manutenção da criança e do adolescente na escola, já que a escola parece mais bem adaptada e direcionada para os grupos mais favorecidos economicamente (Inep, 2016). 


\section{Considerações finais}

Podemos perceber, do que foi posto, que existe ainda uma visão pautada apenas na aprendizagem, sem compromisso com a díade ensino-aprendizagem, em que há corresponsabilidade de ambos os lados no processo educacional. A escola, mesmo que vista de forma positiva como um todo, ainda não contempla os alunos (Silva, 2018).

A gravidade de tais dados nos aponta para uma conjuntura que envolve macro e micropolíticas educacionais (Oliveira et al., 2018). A escola não deve ser uma obrigação e não deve carregar em si todas as soluções sociais, tampouco deve ver o aluno como único responsável por seu sucesso ou insucesso escolar, pois isso acaba reforçando essa visão da meritocracia e do sucesso individual, em detrimento dos elementos sociais que devem compor para que esse sucesso aconteça. Nossos dados mostram como os alunos pesquisados ainda se responsabilizam por problemas enfrentados na escola.

Um passo importante é começar a mudar intergeracionalmente essa relação com a Educação. Pais com mais escolarização tendem a valorizar mais esse espaço e estimular seus filhos. Ao mesmo tempo, os professores devem ser preparados para o que deles se espera em uma escola pública. E, em especial, a Educação, enquanto uma importante instituição, deve estar atenta aos aspectos intra e interpsíquicos envolvidos no que significa manter um aluno na escola (Naiff et al., 2008).

O público-alvo de uma escola pública traz à tona os problemas sociais do Brasil, e isso não pode ser negligenciado, nem nas relações interpessoais que acontecem no ambiente escolar, nem tampouco no conteúdo e currículo a ser apresentado. Não acreditar nas potencialidades que esse aluno tem, tanto pelos próprios alunos quanto pelos professores, é dar continuidade à fracassalização do alunado empobrecido (Patto, 1999).

Os alunos veem na escola, conforme observamos nos dados, uma possibilidade de ter um futuro melhor, uma profissão e ajudar a família; nesse sentido, o contínuo dessa percepção positiva deve ser a realização de fato. Sem que haja macropolíticas educacionais que coloquem a escola em relevância como uma política de Estado e não somente como política de Governo, conforme argumenta Silva (2018), e sem preocupação com as 
micropolíticas institucionais que fazem de cada escola um espaço de mudança não avançaremos nesse quesito.

O insucesso escolar não será medido por estatísticas que garantem que a grande maioria das crianças está na escola, porque não basta estar na escola, é preciso a escola estar em cada criança brasileira como um projeto pessoal e identitário, como se consegue com maior êxito nas escolas privadas (Parente, 2018).

A exclusão social passa por vários matizes, e um deles é certamente esse não pertencimento ao ambiente de transmissão de conhecimento cultural que chamamos de escola, e que permite o conhecer e o fazer pensar. Alijamos uma geração de crianças e jovens desse lugar e os vulnerabilizamos para a escolha de outros lugares de pertencimento, outras identidades sociais que os fortaleçam e façam sentido em seu mundo, só que nem sempre são essas escolhas as mais seguras ou desejáveis.

O presente estudo não esgota o tema e propõe cada vez mais, principalmente no momento atual de grandes mudanças em perspectiva nas políticas públicas, atenção à educação como campo de pesquisas interdisciplinares que ajudem a vislumbrar caminhos, e, nestes, direções adequadas ao futuro que esperamos para os estudantes brasileiros.

\section{Referências}

Abranches, A. F. P. S. (2000). Representações sociais dos professores sobre o sucesso e o fracasso escolar. Dissertação de mestrado, Programa de Pós-Graduação em Psicologia da Universidade Federal de Pernambuco, Recife.

Abric, J. C. (1994). Les reprèsentations sociales: aspects theòriques. In J. C. Abric (Org.). Pratiques sociales et reprèsentations (pp. 11-35). Paris: Presses Universitaires de France.

Abric, J. C. (2003). Abordagem estrutural das representações sociais: desenvolvimentos recentes. In P. H. F. Campos \& M. C. S. Loureiro (Orgs.). Representações sociais e práticas educativas (pp. 35-56). Goiânia: Editora da UCG. 
Arevalo, L. R. G. (2005). O ensino fundamental no Brasil: avanços, perplexidades e tendências. Educação e Sociedade, 26(92), 1039-1066.

Bardin, L. (1977). Análise de conteúdo. Lisboa: Edições 70

Bonomo, M., Trindade, Z., Souza, L., \& Coutinho, S. M. S. (2008). Representações sociais e identidade em grupos de mulheres ciganas e rurais. Psicologia, 23(1), 153-181.

Castorina, J. A., \& Kaplan, C. V. (1997). Representaciones sociales y trayectorias educativas: una relación problemática. Educação e Realidade, 22(2), 187-202.

Deschamps, J-C., \& Moliner, P. (2009). A identidade em Psicologia Social: dos processos identitários às representações sociais. Petrópolis, RJ: Vozes.

Fernandes, C., \& Franco, C. (2001). Séries ou ciclos: o que acontece quando os professores escolhem?. In C. Franco (Org.). Avaliação, ciclos e promoção na Educação (pp. 5568). Porto Alegre, RS: Artmed.

Ferraro, A. R., \& Machado, N. C. F. (2002). Da universalização do acesso à escola no Brasil. Educação e Sociedade, XXIII(79), 213-241.

Ferreira, M. C., Assmar, E. M. L., Omar, A. G., Uribe-Delgado, H., Terrones-Gonzáles, A., Silva, J. M. B., Souza, M. A., \& Cisne, M. C. F. (2002). Atribuição de causalidade ao sucesso e ao fracasso escolar: um estudo transcultural Brasil-Argentina-México. Psicologia Reflexão e Crítica, 15(3), 515-527.

Franco, M. L. P. B. (2002). As representações sociais de alunos da $8^{\mathrm{a}}$ série inseridos em oito escolas estaduais do município de São Paulo. Psicologia da Educação, 14(15), 17-37.

Gilly, M. (2001). As representações sociais no campo da Educação. In D. Jodelet (Org.). As representações sociais (pp. 321-342). Petrópolis, RJ: Vozes. 
Gois, A., \& Rocha, C. (2012). Brasil ainda tem 1 milhão de sem escola. Recuperado em 30 julho, 2012, de http://oglobo.globo.com/educacao/brasil-ainda-tem-1-milhao-desem-escola-5626238\#ixzz23dRK0J3a.

Hollanda, M. P. (2001). A teoria das Representações Sociais como Modelo de Análise do Contexto Escolar. In A. S. P. Moreira \& J. C. Jesuíno (Orgs.). Representações Sociais: Teoria e Prática (pp. 450-463). João Pessoa, PB: Editora Universitária.

IBGE (2010). Censo Demográfico 2010. Recuperado em 20 junho, 2012, de http://www.ibge.gov.br.

Instituto Nacional de Estudos e Pesquisas Educacionais - Inep. (2009). Sinopse Estatística da Educação Básica 2009. Recuperado em 25 janeiro, 2011 , de http//: www.inep.gov.br/Basica/Censo/Escolar/Sinopse/sinopse.asp.

Instituto Nacional de Estudos e Pesquisas Educacionais - Inep. (2010). Sinopse Estatística da Educação Básica 2010. Recuperado em 30 maio, 2012, de http//: www.inep.gov.br/Basica/Censo/Escolar/Sinopse/sinopse.asp.

Instituto Nacional de Estudos e Pesquisas Educacionais - Inep. (2011). Dados do Índice de desenvolvimento da Educação Básica (Ideb). Recuperado em 13 agosto, 2012, de http//: www.inep.gov.br/Basica/Censo/Escolar/Sinopse/sinopse.asp.

Instituto Nacional de Estudos e Pesquisas Educacionais - Inep. (2016). Notas Estatísticas do Censo Escolar 2016. Recuperado em 25 agosto, 2017, de http//: www.inep.gov.br/Basica/Censo/Escolar/Sinopse/sinopse.asp.

Jodelet, D. (1984). Représentation sociale: phénomènes, concept et théorie. In S. Moscovici (Org.). Psychologie sociale (pp. 357-378). Paris: Presses Universitaires de France.

Leon, F. L. L., \& Menezes-Filho, N. A. (2002). Reprovação, avanço e evasão escolar no Brasil. Pesquisa e Planejamento Econômico, 32(3), 417-451. 
Maluf, M. R., \& Bardelli, C. (1991). As causas do fracasso escolar na perspectiva de professoras e alunos de uma escola de primeiro grau. Psicologia: Teoria \& Pesquisa, $7(3), 263-271$.

Mattos, C. L. G. (2005). O conselho de classe e a construção do fracasso escolar. Educação e Pesquisa, 37(2), 215-228.

Moscovici, S. (2003). Representações sociais: investigações em Psicologia Social. Petrópolis, RJ: Vozes.

Naiff, L. A. M., Sá, C. P., \& Naiff, D. G. M. (2008). Preciso estudar para ser alguém: memória e representações sociais da Educação escolar. Paideia, 18, 125-138.

Naiff, L. A. M. (2009). Indisciplina e violência na escola: reflexões no (do) cotidiano. Educação Unisinos, 13, 110-116.

Naiff, L. A. M., Benevides, A. S., Naiff, D. G. M, \& Souto, C. (2010). Ensino público e privado: comparando representações sociais de professores sobre suas habilidades. Psicologia em Pesquisa (UFJF), 4, 57-64.

Naiff, L. A. M., Naiff, D. G. M., Gomes, A., Avila R., \& Giobini, P. (2012). Evasão escolar de alunos da educação de jovens e adultos: contribuições da teoria das representações sociais. Anais da Conferência Internacional de Representações Sociais, Évora, Portugal.

Naiff, L. A. M., \& Naiff, D. G. M. (2014). A evasão escolar nas representações sociais de professores do ensino fundamental. Psicologia Argumento, 32(78), 79-88.

Neves, M. B. J., \& Almeida, S. F. C. (1996). O fracasso escolar na $5^{\text {a }}$ série: na perspectiva de alunos repetentes, seus pais e professores. Psicologia: Teoria e Pesquisa, 12(2), $147-$ 156. 
Oliveira, J. S; Borgui, R. F., \& Miranda, E. M. (2018). Educação pública e privada no Brasil e na Argentina: um olhar sobre a legislação. Currículo sem Fronteiras, 18(1), 170-184, jan./abr.

Parente, C. M. D. (2018). Políticas de Educação Integral em Tempo Integral à Luz da Análise do Ciclo da Política Pública. Educação \& Realidade, 43(2), 415-434. Recuperado de https://dx.doi.org/10.1590/2175-623661874.

Patto, M. H. S. (1988). O fracasso escolar como objeto de estudo: anotações sobre as características de um discurso. Cadernos de Pesquisa, 65, 72-77.

Patto, M. H. S. (2010). A produção do fracasso escolar: histórias de submissão e rebeldia. São Paulo: Casa do Psicólogo.

Pereira, M. G., Amaral, V., \& Soares, S. (1997). Identidades sociais e representações sociais de adolescentes acerca da Sida. Análise Psicológica, 4(XV), 617-636.

Rangel, M. (1997). Bom aluno: real ou ideal?. Petrópolis, RJ: Vozes.

Ribeiro, S. C. (1991). A pedagogia da repetência. Estudos Avançados, 12(5), 7-21.

Rodrigues, A., Assmar, E. M. L., \& Jablonski, B. (2007). Psicologia Social. Petrópolis: Vozes.

Ruiz, M. J. F., Silva, A. L. F., \& Batista, M. (2017). A democratização da Educação pública em tempos de ajuste fiscal. Germinal, $9(1), 132-141$.

Silva, M. A. (2018). Qualidade social da Educação pública: algumas aproximações. Cadernos Cedes, 29(78), 216-226.

Souza, D. T. R. (2006). Formação continuada de professores e fracasso escolar: problematizando o argumento da incompetência. Educação e Pesquisa, 32(3), 477492.

Tajfel, H. (1982). Grupos humanos e categorias sociais. Lisboa: Livros Horizonte. 
Vergès. P. (1994). Approche du noyau central: propriétés quantitatives et structurales. In C. Guimelli (Org.). Structures et transformations des représentations sociales (pp. 233253). Lausane: Delachaux et Niestlé.

Wilson, T. C. P. (2003). Relação entre as representações sociais de fracasso escolar de professores do ensino fundamental e sua prática docente. Dissertação de mestrado, Universidade Estácio de Sá.

Zonta, C., \& Meira, M. E. M. (2007). Representações sociais de professores sobre o fracasso escolar. Revista da Educação - Educere et educare, 2(4), 205-217.

Recebido em: 13/4/2018

Aprovado em: $27 / 1 / 2020$ 